\title{
Youth BMI: Levels, Growth and the Maternal Relationship
}

\section{Molly Jacobs*}

Department of Health Sciences Information and Management, College of Allied Health Science, East Carolina University, NC 27858, USA

\begin{abstract}
Objectives: Weight trends established in adolescence continue through adulthood. What causes the overweight onset? The first objective of this study is to determine factors that are important in BMI determination. The second objective is to determine if those same factors influence BMI growth. The final objective determines if biological and non-biological mothers impact BMI differently.
\end{abstract}

Design: Using a longitudinal panel, I determine those factors deterministic in BMI levels in 1997 and in 2011. Then I show the relative importance of household, geographic, environment and genetic factors in BMI growth. I disaggregate the important of maternal nurture and nature using two different model specifications-a pooled model with dummy variables and a disaggregated analysis separating household by the biological status of the maternal figure.

Setting: The National Longitudinal Survey of Youth 1997 consists of a nationally representative sample of approximately 9,000 youths. In Round 1 of the survey both the eligible youth and one of that youth's parents are interviewed, then youths are interviewed annually.

Subjects: A panel of American age 12-17 in the first year of the panel and age 27 to 32 in the final year.

Results: Results suggest that those factors playing a significant role in BMI determination at the beginning of the panel are the same at the end. Maternal BMI, previous BMI level and age are deterministic. Lack of significance in the non-biological dummy and interaction term suggests that nurturing is more deterministic than genetics. However, when the sample is disaggregated by maternal status, the impact of non-biological mothers diminishes slightly particularly at older ages.

Conclusion: Analysis suggests large racial, ethnic and gender differences in BMI growth. Minorities have faster growth. The impact of maternal BMI on youth BMI growth is present, but the strength of the relationship varies by age and model specification.

\section{Keywords: Obesity; Adolescence; BMI; Mother}

\section{Introduction}

Research shows that weight trends associated with BMI (Body Mass Index) perpetuate throughout life-overweight kids become overweight adults-leading to high percentages of overweight individuals at all ages. Despite the persistence of this potentially fatal health condition, there is no solution or cure for this epidemic or it's debilitating physical consequences. Given the tendency of BMI levels established as a youth to continue into adulthood, I turn to the adolescent years to examine the point of obesity onset and its determinants.

This paper uses the National Longitudinal Survey of Youth 1997 (NLSY97) the genetic, environmental and household determinants of BMI over a 15-year period-1997 to 2011. Given the dynamic circumstances characterizing this period of life, deterministic influences could vary over the 15 years.

Analysis considers the impact of maternal BMI on youth BMI questioning the relative importance of nurture versus nature. Nature is considered genetic attributes while nurture is the child-rearing and behavioral influences. The differential impact of biological and non-biological maternal BMI tests the relative impact of nurture and nature on adolescent BMI growth. Results show no difference between biological and non-biological mothers' BMI, suggesting that the maternal impacts stem primarily from their behavioral, child care and verbal influences.

I begin by discussing what is known about BMI and its growth in adolescence in Section 1. Next, I include a description of the data used and essential covariates before evaluating two annual cross section of BMI levels for the beginning and ending panel years (Sections 2 and
3 respectively). Section 4 contains a description of the BMI growth process while Section 5 discusses a simple modeling strategy and various estimation techniques for this process. Finally, I estimate the determinants of BMI change for the 15 years of available youth BMI data, Section 6. In Section 7, I interpret the results.

\section{Evidence from Related Literature}

Research exploring adolescent obesity tests impacts of parental behavior, lifestyle and attitudes [1]. Obesity has been associated with major technological, life style, eating and activity characteristics [2-4].

Obesity rates vary by racial/ethnic group both before and after achievement of full growth [5]. Freedman et al. [6] discovered that black youth experience higher BMI growth, but Markowitz and Cosminsky [7] find the highest rates among Hispanics, and their children [8].

Maternal employment i Watson s positively related to childhood weight [2,9-11]. Fertig, Glomm and Tschernis show this impact varies by mother's educational level since maternal education is typically related to children's diet and exercise habits (Maternal education

${ }^{*}$ Corresponding author: Molly Jacobs, Department of Health Sciences Information and Management, College of Allied Health Science, East Carolina University, E 5th St., Greenville, NC 27858, USA, Tel: 2527446182; E-mail: Jacobsm17@ecu.edu

Received August 02, 2017; Accepted August 28, 2017; Published September 05, 2017

Citation: Jacobs M (2017) Youth BMI: Levels, Growth and the Maternal Relationship. Health Econ Outcome Res Open Access 3: 136. doi: 10.4172/2471-268X/1000136

Copyright: ( 2017 Jacobs M. This is an open-access article distributed under the terms of the Creative Commons Attribution License, which permits unrestricted use, distribution, and reproduction in any medium, provided the original author and source are credited. 
is used in this study as a proxy for income rather than employment status (Maternal education is used in this study as a proxy for income rather than employment status) [12]. Exposure to an overweight mother increased rates of obesity [9] as did low education and certain demographic features-race, sex, and family size.

\section{Results summary}

Empirical work reveals interesting results. First, Hispanic and black males and females respectively have significantly higher BMI growth than other groups. Second, those factors significantly impacting BMI at the beginning of adolescence remain relatively constant as youth age into young adults in their 20s. Third, BMI of both biological and non-biological mothers has a large, positive impact on adolescent BMI growth-robust to pool and independent empirical specification. However, the impact of biological mother remains strong throughout adolescence, while the non-biological impact diminishes as respondent's age.

While many studies have explored childhood obesity and genetic inheritance, mine differs in several ways. I examine youth from a development perspective. I assess the impact of both biological and non-biological parents-attempting to draw an important conclusion about BMI development and maternal characteristics. Also, I.

\section{NLSY97 Data and Descriptive Patterns}

\section{Survey}

Data used in this study comes from the first 15 rounds of the National Longitudinal Survey of Youth 1997 (NLSY97), annual surveys conducted from 1997 to 2011. Self-reported height and weight information is used to calculate BMI-an indicator of body weight to height proportionality. BMI is highly correlated with body fat and can be used to classify individuals as underweight, healthy weight, at risk of overweight or overweight using a nationally accepted rubric [13].

Measurement error is always a concern particularly in survey data. To minimize such error, I carefully went through the panel and created a series of flags for each observation indicating errant, inconsistent and illogical values of height and weight for each year of respondent data. Wherever possible, I attempted to impute values for height from nearby observations. Given the age distribution of the sample, full height is likely achieved early in the sample. Therefore, missing or errant height values were replaced. After summing the flags and evaluating the sample, I removed potentially errant respondents from the sample. The post-cleaning sample includes 4,205 respondents, but was careful to ensure that the sample distribution did not change no sample bias was introduced. Table 1 illustrates the pre- and post-cleaning sample attributes.

\section{BMI growth}

BMI growth rate-calculated by $\left(B M I_{t}-B M I_{t}-1 / B M I_{t-1}\right)$ assesses the speed of adolescent weight development.

\section{Control covariates}

Mean 1997 and 2011 values are listed in Tables 2 and 3 respectively. Region and rural status remain relatively consistent throughout the sample. Note that household size changes as respondents' age-initially four to five, then falling to two or three. Ages increase with time, but regional variables show little variation.

Age: Age $_{\text {it-1 }}$ is age in the previous survey year. Respondents range in age from 12 to 17 in the first year of the survey and are 25 and 32 years old in 2011. Age plays an important role in BMI determination by accounting for natural biological processes. BMI increases with both natural growth and weight gain; however, rates differ by race and gender [14].

Environmental: Household size $_{t-1}$, quantifies the number of household members. Since household circumstances change as youth progress through life, I include household to capture the transition of youth from their family household to one of their own making. Economists found that household characteristics impact BMI through food availability, expenditure and behavior including diet and activity levels [15]. Participation in food programs, nutrient intake and income levels vary by household and impact annual weight [16].

Geographic: Respondents move often throughout their youth and young adulthood. Region of residence and urban status controls capture these geographic transitions. Higher weights have typically been found among adults in rural areas of the south, but race vary by race/ethnicity [17]. While moving to a dense area often results in weight loss, high BMI individuals are unlikely to choose these areas [18].

While environmental effects are generally small, neighborhood characteristics haven proven to impact adult weight with smaller impact on children [19]. Additionally, state and local level price effects could impact adolescent weight $[20,21]$.

Genetic/Environmental: Biological inheritance plays a role in physical development. Mother's BMI has the potential to capture both the genetic disposition (aka, nature) and the child raising circumstances (aka, nurture). The presence of both biological and non-biological mothers in the survey permits these two impacts to be separately analyzed.

Maternal education/Behavior: Maternal education from the NLSY97 is translated into two dummy variables: less than high school and high school completion. Mothers with greater levels of education are thus the reference category.

\begin{tabular}{|c|c|c|c|c|c|}
\multicolumn{6}{|c|}{$\begin{array}{c}\text { NLSY97: Number of Respondents in each Subgroup Before and after } \\
\text { Cleaning }\end{array}$} \\
\hline Subgroup & N & Percent & Cum Frequency & Cum Percent \\
\hline Total & 8,984 & 100 & 8,984 & 100 \\
\hline Missing & 83 & 1 & 83 & 0.92 \\
\hline Black Female & 1,166 & 13 & 1,249 & 13.9 \\
\hline Black Male & 1,169 & 13 & 2,418 & 26.91 \\
\hline Hispanic Female & 924 & 10 & 3,342 & 37.2 \\
\hline Hispanic Male & 977 & 11 & 4,319 & 48.07 \\
\hline White Female & 2,252 & 25 & 6,571 & 73.14 \\
\hline White Male & 2,413 & 27 & 8,984 & 100 \\
\hline Total Male & 4,599 & 51.19 & 4,599 & 51.19 \\
\hline Total Female & 4,385 & 48.81 & 8,984 & 100 \\
\hline & & Post-Cleaning & 100 \\
\hline Total & 4,205 & 100 & 4,205 & 1.05 \\
\hline Missing & 44 & 1.05 & 44 & 13.51 \\
\hline Black Female & 524 & 12.46 & 568 & 24.8 \\
\hline Black Male & 475 & 11.29 & 1,043 & 34.29 \\
\hline Hispanic Female & 399 & 9.49 & 1,442 & 43.76 \\
\hline Hispanic Male & 398 & 9.47 & 1,840 & 70.97 \\
\hline White Female & 1,144 & 27.21 & 2,984 & 100 \\
\hline White Male & 1,221 & 29.04 & 4,205 & 50.44 \\
\hline Total Male & 2,121 & 50.44 & 2,121 & 100 \\
\hline Total Female & 1,084 & 49.56 & 4,205 & \\
\hline & & & \\
\hline
\end{tabular}

Table 1: Sample distribution before and after data cleaning. 
Citation: Jacobs M (2017) Youth BMI: Levels, Growth and the Maternal Relationship. Health Econ Outcome Res Open Access 3: 136. doi: 10.4172/2471-268X/1000136

Page 3 of 9

\begin{tabular}{|c|c|c|c|c|c|c|c|c|}
\hline \multicolumn{9}{|c|}{ NLSY97: Covariate Means and Simple Statistics by Gender 1997} \\
\hline Gender & $\mathbf{N}$ & Variable & $\mathbf{N}$ & Mean & Median & Std. Dev. & Min. & Max. \\
\hline \multirow{12}{*}{ Male } & \multirow{12}{*}{2,121} & $\mathrm{BMI}_{1997}$ & 2,121 & 21.96 & 21.11 & 4.20 & 12.20 & 49.92 \\
\hline & & $\mathrm{Age}_{1997}$ & 2,121 & 14.77 & 14.80 & 1.44 & 12.20 & 18.20 \\
\hline & & Hispanic & 2,121 & 0.19 & 0.00 & 0.39 & 0.00 & 1.00 \\
\hline & & Black & 2,121 & 0.22 & 0.00 & 0.42 & 0.00 & 1.00 \\
\hline & & Household Size $_{1997}$ & 2,121 & 4.51 & 4.00 & 1.45 & 2.00 & 16.00 \\
\hline & & Urban $_{1997}$ & 2,121 & 0.72 & 1.00 & 0.45 & 0.00 & 1.00 \\
\hline & & Northeast $_{1997}$ & 2,121 & 0.17 & 0.00 & 0.38 & 0.00 & 1.00 \\
\hline & & South $_{1997}$ & 2,121 & 0.35 & 0.00 & 0.48 & 0.00 & 1.00 \\
\hline & & Mothers BMI & 1,567 & 27.11 & 25.74 & 6.32 & 15.11 & 54.92 \\
\hline & & $\begin{array}{l}\text { Mothers Education } \\
\text { Less than High } \\
\text { School } \\
\end{array}$ & 1,975 & 0.19 & 0.00 & 0.39 & 0.00 & 1.00 \\
\hline & & $\begin{array}{l}\text { Mothers Education } \\
\text { High School }_{1997}\end{array}$ & 1,975 & 0.36 & 0.00 & 0.48 & 0.00 & 1.00 \\
\hline & & $\begin{array}{l}\text { Non Biological } \\
\text { Mom }_{1997}\end{array}$ & 1,669 & 0.06 & 0.00 & 0.25 & 0.00 & 1.00 \\
\hline \multirow{12}{*}{ Female } & \multirow{12}{*}{2,084} & $\mathrm{BMI}_{1997}$ & 2,084 & 21.33 & 20.60 & 3.98 & 12.05 & 51.37 \\
\hline & & $\mathrm{Age}_{1997}$ & 2,084 & 14.77 & 14.80 & 1.43 & 12.20 & 18.30 \\
\hline & & Hispanic & 2,084 & 0.19 & 0.00 & 0.39 & 0.00 & 1.00 \\
\hline & & Black & 2,084 & 0.25 & 0.00 & 0.43 & 0.00 & 1.00 \\
\hline & & Household Size $_{1997}$ & 2,084 & 4.57 & 4.00 & 1.58 & 2.00 & 16.00 \\
\hline & & Urban $_{1997}$ & 2,084 & 0.72 & 1.00 & 0.45 & 0.00 & 1.00 \\
\hline & & Northeast $_{1997}$ & 2,084 & 0.16 & 0.00 & 0.37 & 0.00 & 1.00 \\
\hline & & South $_{1997}$ & 2,084 & 0.38 & 0.00 & 0.48 & 0.00 & 1.00 \\
\hline & & Mothers BMI & 1,614 & 26.61 & 25.68 & 5.78 & 16.31 & 53.25 \\
\hline & & $\begin{array}{l}\text { Mothers Education } \\
\text { Less than High } \\
\text { School } \\
{ }_{1997}\end{array}$ & 1,974 & 0.21 & 0.00 & 0.41 & 0.00 & 1.00 \\
\hline & & $\begin{array}{l}\text { Mothers Education } \\
\text { High School }_{1997}\end{array}$ & 1,974 & 0.34 & 0.00 & 0.47 & 0.00 & 1.00 \\
\hline & & $\begin{array}{l}\text { Non Biological } \\
\text { Mom }_{1997}\end{array}$ & 1,706 & 0.06 & 0.00 & 0.24 & 0.00 & 1.00 \\
\hline
\end{tabular}

Table 2: Covariate means and simple statistics by gender: NLSY97 1997.

\section{Annual Cross Sections}

\section{Determinants of BMI in 1997 and 2011}

Mean values are listed in Table 3 and 4. Surprisingly, mean values in 2011 are like those in 1997. The model includes the geographic/ environmental covariates and key maternal determinants, Equation (1).

$\ln B M I_{I 1997,2011}$ *

$=\beta_{0}+\beta_{1}$ Age $_{i 1997,2011}+\beta_{2}$ Hispanic $_{i 1997,2011}+\beta_{3}$ Black $_{i 1997,2011}$

$+\beta_{4}$ Northeast $_{i 1997,2011}+\beta_{5}$ South $_{i 1997,2011}+\beta_{6}$ Urban $_{i 1997,2011}$

$+\beta_{7}$ Household $_{i 1997,2011}+\beta_{8}$ Mother Education Less than Highschool ${ }_{i 1997,2011}$

$+\beta_{9}$ Mother Education Highschool $_{i 1997,2011}+\beta_{10} \ln$ Mothers $B M I_{i 1997,2011}$

$+\beta_{11}$ Non Bio $\log$ ical Mother ${ }_{1997,2011}+\beta_{12} \ln {\text { Mothers } B M I_{i 1997,2011}}$

${ }^{*}$ Non Bio log ical Mother ${ }_{i 1997,2011}+\varepsilon_{i}$

OLS estimates are reported in Table 4. Most covariates characteristics do not play a significant role in either year. Three interesting results appear. First, BMI tends to be age-dependent. Age increases BMI by two to three percent per year between years. Second, racial/ethnic profiles differ by gender. Black females have over six percent higher BMI, but Hispanic females have no differential. The opposite is true for males-Hispanics have four percent higher BMI with black insignificant.

Finally, maternal BMI has a large effect, with an elasticity of roughly 0.2. The significance of maternal BMI reflects two effects: genetic and environmental. Given that both biological and non-biological mothers are included in this term, the positive relationship reflects inherited metabolic/physical as well as behavioral characteristics. Additionally, many are likely to share both households with their mothers-capturing some geographic and lifestyle characteristics.

Key covariates of non-biological mother and the BMI interaction show no significance. While there is only a small sample of nonbiological mothers, this result does suggest that there is little or no difference between the BMI of respondents with biological and nonbiological mothers-the impact of maternal nurturing is nearly as important as inherited genetic attributes. Table 5 explores possible differential impact of biological and non-biological maternal. Direct effects are slightly larger for biological mothers, but this could be due to the disproportionate number of these mothers in the sample. Impacts also increase with the value of the maternal BMI.

To ensure that maternal BMI did not simply capture individual level fixed effects, I ran the 2011 regression model adding $\operatorname{lnBMI}{ }_{1997}$ as an independent variable. However, the results remained consistent suggesting that maternal BMI results are robust to individual fixed effects.

\section{BMI Growth: Panel Conditions}

\section{Stationarity of BMI growth}

In this phase of analysis, I utilize BMI growth as the dependent 
Citation: Jacobs M (2017) Youth BMI: Levels, Growth and the Maternal Relationship. Health Econ Outcome Res Open Access 3: 136. doi: 10.4172/2471-268X/1000136

Page 5 of 9

\begin{tabular}{|c|c|c|c|c|}
\hline \multicolumn{5}{|c|}{ NLSY97: Impact of Biological and Non-Biological Mothers' BMI on Respondent BMI by Gender } \\
\hline \multirow{2}{*}{$\begin{array}{c}\text { BMI } \\
\text { Maternal BMI }\end{array}$} & \multicolumn{2}{|c|}{ Male } & \multicolumn{2}{|c|}{ Female } \\
\hline & Biological & Non-Biological & Biological & Non-Biological \\
\hline & \multicolumn{2}{|c|}{ InMom BMI ${ }_{1997}\left(0.189-0.023 *\right.$ Non-Biological Mom $\left._{1997}\right)$} & \multicolumn{2}{|c|}{ InMom BMI ${ }_{1997}\left(0.251-0.085^{\star}\right.$ Non-Biological Mom $\left._{1997}\right)$} \\
\hline 12 & 0.469647 & 0.412495 & 0.623712 & 0.412495 \\
\hline 20 & 0.566193 & 0.497292 & 0.751929 & 0.497292 \\
\hline 27 & 0.622913 & 0.547109 & 0.827255 & 0.547109 \\
\hline 50 & 0.739372 & 0.649396 & 0.981918 & 0.649396 \\
\hline \multicolumn{5}{|c|}{ Dependent Variable: $\operatorname{lnBMI}$} \\
\hline \multicolumn{5}{|c|}{ Source: NLSY 1997} \\
\hline
\end{tabular}

Table 5: Impact of mothers BMI on respondent BMI by gender.

variable. I perform Augmented Dickey Fuller (ADF) tests of BMI growth rate to ensure stationarity of the distributions.

\section{Relationship to covariates}

Using a Generalized Linear Model (GLM), I determine BMI growth impacts for both sexes. GLM is optimized using maximum likelihood techniques and accounts for the dependency of observations by specifying a working correlation structure. Residuals are iteratively refit to account for repeated measure in longitudinal data. Environmental, genetic, household and regional factors serve as proxies for unobserved diet, physical activity and other health behaviors [10].

The first model, referred to as the pooled model, uses the entire panel and estimates BMI growth over the sample year. This model includes respondents with both biological and non-biological mothers and uses a dummy variable to distinguish between the two types. The second model, referred to as the singular model, analyzes respondents with biological and non-biological mothers separately and determines the unique impact of biological and non-biological maternal BMI within each individual model.

\section{Dynamic BMI Frameworks}

\section{Pooled model}

The pooled model includes independent variables control for demographic and environmental characteristics. The dependent variable is considered the amount of year-to-year change, or growth rate-a function of the initial BMI level. For example, an underweight individual experiencing a 1.9 BMI-unit change (18.5 to $20.4 \mathrm{BMI}$ ) has a 10 percent growth, whereas an individual with double the BMI who experiences a 1.9 BMI-unit change (37 to $38.9 \mathrm{BMI}$ ), only experiences 5 percent growth, Equation (2).

$\left(\Delta \ln B M I_{I}\right) * 100=\left(\ln B M I_{i t}-\ln B M I_{i, t-1}\right) * 100$

$=\alpha_{i}+\beta_{1} \ln B M I_{i t-1}+\beta_{2}$ Age $_{i t-1}+\beta_{3}$ Age $_{i, t-1} * \ln B M I_{i t-1}+\beta_{4}$ South $_{i t-1}$

$+\beta_{5}$ Northeast $_{i t-1}+\beta_{6}$ Urban $_{i t-1}+\beta_{7}$ Household Size $_{i t-1}+\beta_{8}$ Household Income $_{i t-1}$

$+\beta_{9}$ Mother Education Less than $H S_{i 1997}+\beta_{9}$ Mother Education $H S_{i 1997}$

$+\beta_{11} \ln$ Mother's Education BMI $_{i 1997}+\beta_{12}$ NonBio $\log$ icalMother $_{i 1997}+\beta_{13} \ln$ Mother' $^{\prime} B M I_{i 1997}$

*NonBio $\log$ icalMother $_{i 1997}+\beta_{14} X_{i t-1}+\mu_{i t}$

$B M I_{i t}$ and $B M I_{i t-1}$ represent BMI in the current year $(t)$ and the previous year (t-1) for individual $A g e_{i t-1} * \ln B M I_{i, t-1} * X_{i t-1}$ then represents the rate of BMI change. Age $\mathrm{it}_{\mathrm{it}-1}$ is age in the previous period while any interaction effects between age and previous BMI are captured by $\operatorname{Ag}_{i t-1} * \ln B M I_{i, t-1} * X_{i t-1}$, which accounts for individual characteristics and controls. Finally, $\mu_{\mathrm{it}}$ representing the error term. The possible correlation of observations over time not just over a single individual could be an issue of concern. However, within model determination of the correlation matrix ensures that estimates are unbiased and consistent.

\section{Singular model}

The singular model includes a similar list of covariates to those discussed above. However, respondents with biological non-biological mothers are analyzed separately rather than using $s$ dummy variable, Equation (3).

$\left(\Delta \ln B M I_{i}\right) * 100=\left(\ln B M I_{i t}-\ln B M I_{i, t-1}\right) * 100=\alpha_{i}+\beta_{1} \ln B M I_{i t-1}+\beta_{2} \operatorname{Age}_{i t-1}+\beta_{3} \operatorname{Age}_{i t-1} *$ $\ln$ BMI $_{i, t-1}+\beta_{4}$ South $_{i t-1}+\beta_{5}$ Northeast $_{i t-1}+\beta_{6}$ Urban $_{i t-1}+\beta_{7}$ Household Size $_{i t-1}+$

$\beta_{8}$ Household Income $i t-1+\beta_{9}$ Mothers Education Less than $H S_{i 1997}+\beta_{10}$ Mothers Education $H_{i 1997}+$ $\beta_{11} \ln$ Mother' $s B M I_{i 1997}+\mu_{i t}$

\section{Use of previous BMI}

The decision to include previous BMI $\left(\ln B M I_{i t-1}\right)$ in the model is theoretical. Studies have shown that previous BMI is the most import predictor of current BMI [22]. Economists have proven that previous levels control negative statistical impacts of heteroscedasticity [23].

\section{Empirical Estimation}

\section{Pooled model}

I first estimate Equation 2 separately for males and females including. Since the relationship between maternal weight and respondent weight could potentially vary across age groups, I then re-estimate both models dividing each into two age groups-12-20 and 21-32.

\section{Singular model}

I then estimate Equation 3 separately by gender and biological status of the maternal figure. I then re-estimate the models dividing the sample by age.

\section{Results}

\section{Pooled model}

Results Table 6 for all ages and Table 7 for age subgroups.

\section{Singular model}

Results Table 8 for all ages and Table 9 for age subgroups.

I will begin by discussing the models including all age groups. Results are similar the cross-sectional analysis for both the pooled and singular model. BMI is age dependent-higher growth observed at younger ages. BMI, age and their interaction estimates are consistent and significant. Being black, for women, and being Hispanic, for men, increases BMI growth rates. Both pooled and singular estimates are largely unaffected by demographic and socioeconomic characteristics. Maternal factors and lagged BMI levels are the largest determinantsconsistent with earlier findings.

Both genders and model specifications show the maternal BMI 
Citation: Jacobs M (2017) Youth BMI: Levels, Growth and the Maternal Relationship. Health Econ Outcome Res Open Access 3: 136. doi: 10.4172/2471-268X/1000136

Page 6 of 9

\begin{tabular}{|c|c|c|c|c|}
\hline \multicolumn{5}{|c|}{ NLSY97: Pooled Regression Model by Gender } \\
\hline & \multicolumn{2}{|c|}{ Male } & \multicolumn{2}{|c|}{ Female } \\
\hline & \multicolumn{4}{|c|}{ Model Fit } \\
\hline QIC & \multicolumn{2}{|c|}{20493.595} & \multicolumn{2}{|c|}{20325.839} \\
\hline $\mathbf{N}$ & \multicolumn{2}{|c|}{20,416} & \multicolumn{2}{|c|}{20,263} \\
\hline \multicolumn{5}{|c|}{ Results } \\
\hline Variable & Parameter & Std. Err & Parameter & Std. Err \\
\hline Intercept & $0.811^{* \star *}$ & 0.0543 & $0.7403^{* *}$ & 0.0513 \\
\hline $\operatorname{lnBMI}_{\mathrm{t}-1}$ & $-0.3189^{* * *}$ & 0.0172 & $-0.3055^{\star * *}$ & 0.0165 \\
\hline Age $_{t-1}$ & $-0.0103^{* * *}$ & 0.0021 & $-0.0123^{* * *}$ & 0.002 \\
\hline $\operatorname{lnBMI}_{\mathrm{t}-1}{ }^{*} \mathrm{Agg} \mathrm{t}_{\mathrm{t}-1}$ & $0.0037^{* * *}$ & 0.0007 & $0.0043^{* * *}$ & 0.0006 \\
\hline Hispanic & $0.0122^{* * *}$ & 0.0031 & 0.0026 & 0.0031 \\
\hline Black & -0.0016 & 0.0027 & $0.0113^{* * *}$ & 0.0029 \\
\hline Household Size $_{t-1}$ & -0.0003 & 0.0003 & $-0.0011^{* * *}$ & 0.0004 \\
\hline Urban $_{\mathrm{t}-1}$ & -0.0014 & 0.0013 & 0.0012 & 0.0015 \\
\hline Northeast ${ }_{t-1}$ & 0.0005 & 0.0025 & -0.0027 & 0.0026 \\
\hline South $_{\mathrm{t}-1}$ & -0.0025 & 0.0019 & 0.0003 & 0.002 \\
\hline Mothers Education Less than High School ${ }_{1997}$ & 0.003 & 0.0031 & 0.0047 & 0.0033 \\
\hline Mothers Education High School ${ }_{1997}$ & $0.0047^{\star \star}$ & 0.0024 & 0.0003 & 0.0024 \\
\hline InMothers $\mathrm{BMI}_{1997}$ & $0.0586^{* * *}$ & 0.0054 & $0.0643^{\star * *}$ & 0.0062 \\
\hline Non Biological Mom 1997 & 0.0894 & 0.0656 & 0.0786 & 0.0685 \\
\hline InMothers $\mathrm{BMI}_{1997}{ }^{*}$ Non Biological Mom ${ }_{1997}$ & -0.0301 & 0.0199 & -0.0243 & 0.0207 \\
\hline \multicolumn{5}{|c|}{ Dependent Variable: $\operatorname{InBMI}-\operatorname{InBMI} I_{t-1}=B M I$ Growth Rate } \\
\hline \multicolumn{2}{|c|}{ Source: NLSY 1997} & & & \\
\hline \multicolumn{5}{|c|}{ Statistical Significance: ${ }^{*}(0.10),{ }^{* *}(0.05),{ }^{* * *}(0.01)$} \\
\hline
\end{tabular}

Table 6: Pooled regression by gender NLSY 1997-2011.

\begin{tabular}{|c|c|c|c|c|c|c|c|c|}
\hline \multicolumn{9}{|c|}{ Panel Regression with Covariates by Gender NLSY 1997-2011 } \\
\hline & \multicolumn{2}{|c|}{ Male } & \multicolumn{2}{|c|}{ Female } & \multicolumn{2}{|c|}{ Male } & \multicolumn{2}{|c|}{ Female } \\
\hline & \multicolumn{4}{|c|}{ Model Fit } & \multicolumn{4}{|c|}{ Model Fit } \\
\hline QIC & 6981.323 & & 7048.879 & & 13450.918 & & 13230.736 & \\
\hline \multirow[t]{2}{*}{$\mathrm{N}$} & 6,969 & & 7,037 & & 13,447 & & 13,226 & \\
\hline & \multicolumn{4}{|c|}{ Results Age $12-20$} & \multicolumn{4}{|c|}{ Results Age 21-32 } \\
\hline Variable & Parameter & Std. Err & Parameter & Std. Err & Parameter & Std. Err & Parameter & Std. Err \\
\hline Intercept & 0.06 & 0.0876 & $-0.1836^{\star \star}$ & 0.0888 & $0.4991^{* * *}$ & 0.0868 & $0.4681^{* * *}$ & 0.082 \\
\hline $\operatorname{lnBMI}_{\mathrm{t}-1}$ & -0.0378 & 0.0288 & 0.0385 & 0.0291 & $-0.1605^{\star \star *}$ & 0.027 & $-0.1532^{* \star *}$ & 0.0258 \\
\hline Age & $0.0121^{* * *}$ & 0.0046 & $0.0183^{\star * *}$ & 0.0047 & $-0.0181^{* * *}$ & 0.0036 & $-0.0164^{* * *}$ & 0.0033 \\
\hline InBMI*Age & $-0.0037^{* *}$ & 0.0015 & $-0.0058^{* * *}$ & 0.0016 & $0.0054^{\star * *}$ & 0.0011 & $0.005^{\star * * *}$ & 0.001 \\
\hline Hispanic & $0.0048^{\star *}$ & 0.0023 & -0.0007 & 0.0024 & $0.0027^{* *}$ & 0.0012 & -0.0003 & 0.0016 \\
\hline Black & -0.0023 & 0.0023 & 0.0027 & 0.0021 & -0.0018 & 0.0011 & 0.002 & 0.0015 \\
\hline Household Size & $0.0017^{\star *}$ & 0.0006 & -0.0004 & 0.0005 & -0.0003 & 0.0003 & $-0.0014^{* * *}$ & 0.0004 \\
\hline Urban & 0.0015 & 0.0019 & $-0.0036^{* *}$ & 0.0018 & $-0.002^{\star *}$ & 0.001 & $0.0031^{* *}$ & 0.0014 \\
\hline Northeast & 0.0014 & 0.0023 & -0.0021 & 0.0023 & 0.0013 & 0.0012 & -0.0011 & 0.0016 \\
\hline South & -0.0018 & 0.0019 & -0.002 & 0.0018 & -0.0007 & 0.0009 & -0.0006 & 0.0012 \\
\hline $\begin{array}{l}\text { Mothers Education Less than High } \\
\text { School }\end{array}$ & -0.0024 & 0.0023 & 0.0011 & 0.0025 & 0.0019 & 0.0012 & 0.0018 & 0.0016 \\
\hline Mothers Education High School & -0.0003 & 0.0019 & -0.0023 & 0.0017 & $0.0023^{* *}$ & 0.0009 & 0.0007 & 0.0013 \\
\hline InMothers BMI & $0.0206^{\star * *}$ & 0.0041 & $0.0266^{\star \star *}$ & 0.0045 & $0.0153^{* * *}$ & 0.0021 & $0.0129^{* \star *}$ & 0.003 \\
\hline Non Biological Mom & 0.051 & 0.046 & 0.0992 & 0.0605 & 0.037 & 0.0331 & -0.0228 & 0.03 \\
\hline InMothers BMI*Non Biological Mom & -0.0167 & 0.0136 & -0.0314 & 0.0186 & -0.0117 & 0.0103 & 0.0074 & 0.0091 \\
\hline \multicolumn{9}{|c|}{ Dependent Variable: InBMI-InBMI=BMI Growth Rate } \\
\hline \multicolumn{9}{|c|}{ Source: NLSY 1997} \\
\hline \multicolumn{9}{|c|}{ Statistical Significance: ${ }^{*}(0.10),{ }^{* *}(0.05),{ }^{* * *}(0.01)$} \\
\hline
\end{tabular}

Table 7: Pooled regression by age NLSY 1997-2011.

impact on respondent BMI growth to be positive and highly significant. The higher a mother's BMI, the faster is a respondent's BMI growth. I again address the question of what matter more to youth BMI growth, nurture or nature. Lack of strong significance for the non-biological mother dummy and its interaction suggests that the biological element is less important in determining adolescent BMI growth than intrinsic maternal attributes-child rearing, meal planner, food shopper and value installation.

However, when the sample is separated by the mother's biological status interesting differences appear. As shown in Table 8 , the age, interaction and ethnic impacts disappear for households with a nonbiological maternal figure. Regional and household size impacts begin 
to show slight significance for males and females respectively. Not surprisingly, the significance and magnitude of the maternal BMI impact diminishes slightly for non-biological mothers. Differences in Tables 6 and 8 suggest two interesting conclusions. First, there are differences in households with biological and non-biological mothers aside from the maternal relationship. While these differences cannot be determined within the scope of this analysis, but they appear to be systematic and merit further study. Second, the BMI impact of biological mothers is undoubtedly stronger than that of non-biological mothers-likely a result of the genetic relationship.

Tables 7 and 9 disaggregate the pooled and singular models respectively by age groups. The panel age range includes teens, transitional adolescents and young adults. Including all ages in a single regression forces the age effect on BMI growth to be linear, which it undoubtedly is not. To explore whether the relationship between maternal and respondent BMI differed by age, I separated the sample into two groups-12 to 20 and 21 to 32 . Twenty-one was chosen as the demarcating age given the legal implications of this milestone.

Table 7 shows that, while the maternal BMI impact continues to be positive and significant, the impact of previous BMI level diminishes for the younger age group. Additionally, the age effect is positive for the younger age groups and negative for older ages. Similarly, the interaction impact is negative and significant for youth and positive and significant for young adults. This suggests faster BMI growth for younger adolescents and much slower rates of increase for young adults. Furthermore, household size and regional covariates become slightly significant.

Table 9 divides the sample by gender, age and biological relationship of the household maternal figure. The BMI impact of biological mother is significant for both genders and age categories; however, the BMI impact of non-biological mothers is only barely significant for male and females even though it remains highly significant for young adults. Among households with non-biological mothers, more environmental and regional covariates appear deterministic. Table 9 supports the earlier conclusions that not only does, is maternal BMI more deterministic for biological mothers, but also that households with non-biological mothers are systematically different in ways outside the scope of this analysis.

\section{Conclusion}

Studies have shown that once unhealthy weight is established, it persists through adulthood [24]. However, these studies fail to acknowledge the age-dependency of adolescent weight or disentangle the influences of nature and nurture. This study uses a generalized estimation model for longitudinal data analysis to control for repeated individual observations and time-dependent co-variations. This technique evaluates the determinants of BMI levels and growth of a 15 -year panel as youth age from children to young adults.

Results reveal that BMI development is impacted primarily by age and previous BMI, and strongly impact by maternal BMI. However, the strength of the BMI relationship varies by the biological relationship of the household maternal figure and respondent's age. The higher a mother's BMI, the higher the adolescent's BMI growth rate. Testing two distinct model specifications-a pooled model and a singular model that separates households by the maternal relationship-reveals that the age, interaction and ethnic impacts disappear for households with non-biological maternal figures. However, regional and household size covariates emerge as deterministic in these households [25]. While the interaction effect in the pooled model suggests no difference in biological and non-biological mothers, separating the sample reveals distinct differences in households with biological and non-biological mothers. Differences appear more pronounced among older respondents.

These household differences and the role they play in BMI growth merits further study. The differences that emerge in the two model specifications provides partial support to the argument that maternal nurturing is as important as genetic relations in weight development, but reveals that this result varies by age. These results are insightful, but

\begin{tabular}{|c|c|c|c|c|c|c|c|c|}
\hline \multicolumn{9}{|c|}{ Singular Regression with Covariates by Gender NLSY 1997-2011 } \\
\hline & \multicolumn{2}{|c|}{ Male } & \multicolumn{2}{|c|}{ Female } & \multicolumn{2}{|c|}{ Male } & \multicolumn{2}{|c|}{ Female } \\
\hline & \multicolumn{4}{|c|}{ Model Fit } & \multicolumn{4}{|c|}{ Model Fit } \\
\hline QIC & \multicolumn{2}{|c|}{19546.8636} & \multicolumn{2}{|c|}{19474.214} & \multicolumn{2}{|c|}{962.6201} & \multicolumn{2}{|c|}{857.3649} \\
\hline \multirow[t]{2}{*}{$\mathrm{N}$} & 19 , & & 19 , & & & & 84 & \\
\hline & \multicolumn{4}{|c|}{ Biological Mother } & \multicolumn{4}{|c|}{ Non-biological Mother } \\
\hline Variable & Parameter & Std. Err & Parameter & Std. Err & Parameter & Std. Err & Parameter & Std. Err \\
\hline Intercept & $0.8131^{* * *}$ & 0.0556 & $0.7562^{\star * *}$ & 0.0521 & $0.5731^{\star *}$ & 0.2136 & $0.484^{* *}$ & 0.2399 \\
\hline InBMI & $-0.3198^{\star * *}$ & 0.0177 & $-0.3119^{* * *}$ & 0.0168 & $-0.2047^{* * *}$ & 0.0688 & $-0.1783^{* *}$ & 0.0803 \\
\hline Age & $-0.0101^{* * *}$ & 0.0021 & $-0.0125^{\star * *}$ & 0.002 & -0.0085 & 0.0085 & -0.0104 & 0.0105 \\
\hline InBMI*Age & $0.0037^{\star * *}$ & 0.0007 & $0.0044^{* * *}$ & 0.0006 & 0.0029 & 0.0027 & 0.0034 & 0.0034 \\
\hline Hispanic & $0.0113^{* * *}$ & 0.0031 & 0.0028 & 0.0032 & $0.0269^{* *}$ & 0.0132 & -0.0028 & 0.0136 \\
\hline Black & -0.0004 & 0.0028 & $0.0119^{* * *}$ & 0.003 & -0.0157 & 0.0086 & -0.0013 & 0.0062 \\
\hline Household Size & -0.0004 & 0.0004 & $-0.0011^{* * *}$ & 0.0004 & -0.0007 & 0.0014 & -0.0023 & 0.0015 \\
\hline Urban & -0.001 & 0.0014 & 0.0011 & 0.0015 & -0.0047 & 0.0056 & 0.0021 & 0.0073 \\
\hline Northeast & 0.0014 & 0.0025 & -0.0027 & 0.0026 & $-0.0273^{\star *}$ & 0.0124 & -0.0155 & 0.0109 \\
\hline South & -0.0027 & 0.002 & -0.0002 & 0.0021 & -0.0064 & 0.0064 & 0.0063 & 0.0068 \\
\hline $\begin{array}{c}\text { Mothers Education Less than } \\
\text { High School }\end{array}$ & 0.0035 & 0.0032 & 0.0047 & 0.0034 & 0.0017 & 0.0101 & 0.0066 & 0.0084 \\
\hline Mothers Education High School & $0.0049^{* *}$ & 0.0024 & 0.0004 & 0.0025 & 0.0017 & 0.009 & 0.0017 & 0.0071 \\
\hline InMothers BMI & $0.0586^{\star \star *}$ & 0.0055 & $0.0655^{\star \star *}$ & 0.0063 & $0.0283^{* * *}$ & 0.0119 & $0.0264^{\star *}$ & 0.0118 \\
\hline \multicolumn{9}{|c|}{ Dependent Variable: InBMI-InBMI=BMI Growth Rate } \\
\hline \multicolumn{9}{|c|}{ Source: NLSY 1997} \\
\hline \multicolumn{9}{|c|}{ Statistical Significance: ${ }^{*}(0.10),{ }^{* *}(0.05),{ }^{* * *}(0.01)$} \\
\hline
\end{tabular}

Table 8: Singular regression by gender: separate analysis for biological and non-biological mothers. 
Citation: Jacobs M (2017) Youth BMI: Levels, Growth and the Maternal Relationship. Health Econ Outcome Res Open Access 3: 136. doi: 10.4172/2471-268X/1000136

Page 8 of 9

\begin{tabular}{|c|c|c|c|c|c|c|c|c|}
\hline \multicolumn{9}{|c|}{ Singular Regression with Covariates by Gender and Age NLSY 1997-2011 } \\
\hline \multicolumn{9}{|c|}{ Male } \\
\hline & \multicolumn{2}{|c|}{ Biological Mother } & \multicolumn{2}{|c|}{ Non-biological Mother } & \multicolumn{2}{|c|}{ Biological Mother } & \multicolumn{2}{|c|}{ Non-biological Mother } \\
\hline QIC & \multicolumn{2}{|c|}{6658.9881} & \multicolumn{2}{|c|}{332.4232} & \multicolumn{2}{|c|}{12837.629} & \multicolumn{2}{|c|}{620.5091} \\
\hline $\mathrm{N}$ & \multicolumn{2}{|c|}{6,647} & \multicolumn{2}{|c|}{322} & \multicolumn{2}{|c|}{12,835} & \multicolumn{2}{|c|}{612} \\
\hline & \multicolumn{4}{|c|}{ Age $12-20$} & \multicolumn{4}{|c|}{ Age $21-32$} \\
\hline Variable & Parameter & Std. Err & Parameter & Std. Err & Parameter & Std. Err & Parameter & Std. Err \\
\hline Intercept & 0.0748 & 0.0907 & -0.2689 & 0.287 & $0.5116^{* * *}$ & 0.0879 & 0.2715 & 0.483 \\
\hline InBMI & -0.0425 & 0.0298 & 0.0669 & 0.0907 & $-0.1636^{* * *}$ & 0.0273 & -0.0939 & 0.1486 \\
\hline Age & $0.011^{* *}$ & 0.0048 & $0.0362^{* * *}$ & 0.014 & $-0.0187^{* * *}$ & 0.0036 & -0.0052 & 0.0188 \\
\hline InBMI*Age & $-0.0033^{* *}$ & 0.0016 & -0.0116 & 0.0045 & $0.0055^{\star * *}$ & 0.0011 & 0.0017 & 0.0059 \\
\hline Hispanic & $0.0042^{*}$ & 0.0023 & 0.0194 & 0.0167 & $0.0023^{*}$ & 0.0012 & 0.0176 & 0.0089 \\
\hline Black & $-0.0023^{* * *}$ & 0.0023 & -0.0061 & 0.0102 & -0.0013 & 0.0011 & $-0.0121^{*}$ & 0.0063 \\
\hline Household Size & $0.0018^{* * *}$ & 0.0006 & -0.0009 & 0.0022 & -0.0002 & 0.0003 & -0.0013 & 0.0016 \\
\hline Urban & 0.0013 & 0.0019 & 0.0048 & 0.0077 & -0.0019 & 0.001 & -0.0049 & 0.0046 \\
\hline Northeast & 0.0019 & 0.0023 & -0.0159 & 0.0141 & 0.0018 & 0.0012 & $-0.0226^{\star *}$ & 0.0104 \\
\hline South & -0.0018 & 0.002 & -0.0059 & 0.0087 & -0.0006 & 0.001 & -0.0045 & 0.0055 \\
\hline $\begin{array}{c}\text { Mothers Education Less than } \\
\text { High School }\end{array}$ & -0.002 & 0.0024 & -0.0084 & 0.0147 & 0.0019 & 0.0012 & 0.004 & 0.0067 \\
\hline Mothers Education High School & -0.0004 & 0.0019 & -0.0026 & 0.0119 & 0.0022 & 0.0009 & 0.0038 & 0.0055 \\
\hline InMothers BMI & $0.0202^{* * *}$ & 0.0041 & $0.0281^{*}$ & 0.0171 & $0.015^{* * *}$ & 0.0021 & 0.0133 & 0.0102 \\
\hline \multicolumn{9}{|c|}{ Female } \\
\hline & \multicolumn{2}{|c|}{ Biological Mother } & \multicolumn{2}{|c|}{ Non-biological Mother } & \multicolumn{2}{|c|}{ Biological Mother } & \multicolumn{2}{|c|}{ Non-biological Mother } \\
\hline QIC & 6763.8308 & & 287.5712 & & 12668.351 & & 561.0439 & \\
\hline \multirow[t]{2}{*}{$\mathrm{N}$} & 6,754 & & 283 & & 12,663 & & 563 & \\
\hline & \multicolumn{4}{|c|}{ Age $12-20$} & \multicolumn{4}{|c|}{ Age $21-32$} \\
\hline Variable & Parameter & Std. Err & Parameter & Std. Err & Parameter & Std. Err & Parameter & Std. Err \\
\hline Intercept & $-0.1636^{*}$ & 0.0883 & $-1.0293^{*}$ & 0.5284 & $0.4558^{* * *}$ & 0.0833 & $0.7934^{*}$ & 0.4311 \\
\hline InBMI & 0.0322 & 0.0289 & $0.3631^{* *}$ & 0.1743 & $-0.1483^{* * *}$ & 0.0263 & $-0.2842^{\star *}$ & 0.1361 \\
\hline Age & $0.017^{* * *}$ & 0.0047 & $0.0652^{* *}$ & 0.0286 & $-0.0159^{* * *}$ & 0.0034 & $-0.0312^{*}$ & 0.0171 \\
\hline InBMI*Age & -0.0054 & 0.0016 & $-0.0215^{\star *}$ & 0.0094 & $0.0048^{\star * *}$ & 0.0011 & $0.0099^{*}$ & 0.0054 \\
\hline Hispanic & -0.0003 & 0.0024 & 0.01 & 0.0182 & 0 & 0.0016 & -0.0085 & 0.0079 \\
\hline Black & 0.0032 & 0.0022 & -0.0029 & 0.0102 & 0.0024 & 0.0015 & -0.0063 & 0.0042 \\
\hline Household Size & -0.0004 & 0.0005 & -0.0019 & 0.002 & $-0.0014^{* * *}$ & 0.0004 & $-0.0026^{\star *}$ & 0.0011 \\
\hline Urban & $-0.0031^{*}$ & 0.0018 & -0.0105 & 0.0105 & $0.0026^{*}$ & 0.0014 & 0.0084 & 0.0058 \\
\hline Northeast & -0.0006 & 0.0023 & $-0.055^{\star * *}$ & 0.0144 & -0.0013 & 0.0016 & 0.01 & 0.0116 \\
\hline South & -0.0017 & 0.0018 & -0.0132 & 0.0102 & -0.0012 & 0.0013 & $0.0129^{* * *}$ & 0.0048 \\
\hline $\begin{array}{c}\text { Mothers Education Less than } \\
\text { High School }\end{array}$ & 0.0001 & 0.0025 & $0.0225^{\star *}$ & 0.0112 & 0.0022 & 0.0017 & -0.0022 & 0.0064 \\
\hline Mothers Education High School & -0.0025 & 0.0018 & 0.0137 & 0.0098 & 0.0005 & 0.0013 & 0.0036 & 0.0054 \\
\hline InMothers BMI & $0.026^{* \star *}$ & 0.0045 & -0.0109 & 0.0172 & $0.0124^{\star * *}$ & 0.003 & $0.0331^{* * *}$ & 0.0097 \\
\hline & & Depen & /ariable: $\ln B$ & $\mathrm{Al}=\mathrm{BMI} \mathrm{Gro}$ & Rate & & & \\
\hline & & & Source: $\uparrow$ & 997 & & & & \\
\hline & & Statist & gnificance: * & $* *(0.05)$ & 01) & & & \\
\hline
\end{tabular}

Table 9: Singular regression by age: separate analysis for biological and non-biological mothers.

far from complete. I believe further exploration is merited, exploring other factors related to the biological presence in the household.

\section{Acknowledgements}

I wish to acknowledge Donald Parsons for his care and time reviewing drafts and editing the work. I also wish to thank Tara Sinclair and Bryan Boulier for their helpful suggestions. I also wish to acknowledge the National Longitudinal Survey (NLS) which has provided data and resources towards this work.

\section{References}

1. Golan M, Crow S (2004) Parents are key players in the prevention and treatment of weight-related problems. Nutr Rev 62: 39-50.

2. Anderson $P$, Butcher K, Levine $P$ (2003) Economic perspectives on childhood obesity. J Econ Perspect Federal Reserve Bank of Chicago 3: 30-48.

3. Lakdawalla D, Philipson T, Bhattacharya J (2005) Welfare-enhancing technological change and the growth of obesity. Am Econ Rev 95: 253-257.
4. Strasburger V (2011) Children, adolescents, obesity and the media. J Pediatr 128: $201-208$.

5. Kline B, Tobias J (2014) Explaining trends in body mass index using demographic counter factuals. Econom Rev 33: 172-196.

6. Freedman D, Khan K, Serdula M, Ogden C, Dietz W (2006) Racial and ethnic differences in secular trends for childhood bmi, weight, and height. J Obes 14 301-308.

7. Markowitz D, Cosminsky S (2005) Overweight and stunting in migrant Hispanic children in the USA. Econ Hum Biol 3: 215-240.

8. Van Hook J, Balistreri K (2007) Immigrant generation, socioeconomic status, and economic development of countries of origin: A longitudinal study of body mass index among children. Soc Sci Med 65: 976-989.

9. Classen T, Hokayem C (2005) Childhood influences on youth obesity. Econ Hum Biol 3: 165-187.

10. Cawley J, Liu F (2007) Maternal employment and childhood obesity: A search for mechanisms in time use data. NBER pp: 13600. 
Citation: Jacobs M (2017) Youth BMI: Levels, Growth and the Maternal Relationship. Health Econ Outcome Res Open Access 3: 136. doi: $10.4172 / 2471-268 X / 1000136$

11. Ruhm C (2008) Maternal employment and adolescent development. J Labour Econ 15: 958-983.

12. Nayga R, Rodolfo M (2000) Schooling, health knowledge and obesity. J Appl Econ 32: 815-822.

13. Flegal K, Shepherd J, Looker A, Graubard B, Borrud L, et al. (2009) Comparisons of percentage body fat, body mass index, waist circumference and waist-stature ratio in adults. Am J Clin Nutr 89: 500-508

14. Gallagher D, Visser M, Sepulveda D, Pierson R, Harris T, et al. (1996) How useful is body mass index for comparison of body fatness across age, sex and ethnic groups. Am J Epidemiol 143: 228-239.

15. Corral I, Landrine H, Zhao L (2014) Residential segregation and obesity among a national sample of hispanic adults. J Health Psychol 19: 503-508.

16. Starkey L, Gray-Donald K, Kuhnlein H (1999) Nutrient Intake of food bank users is related to frequency of food bank use, household size, smoking, education and country of birth. J Nutr 129: 883-889.

17. Jackson E, Doescher M, Jerant A, Hart G (2005) A national study of obesity prevalence and trends by type of rural county. J Rural Health 21: 140-148.
18. Plantinga A, Bernell S (2007) The association between urban sprawl and obesity: is it a two-way street. J Regional Sci 47: 857-879.

19. Sen B, Memmemeyer S, Gary L (2009) The relationship between neighborhood quality and obesity among children. NBER pp: 14985.

20. Powell L, Chriqui J, Chapoupka F (2009) Associations between state-leve soda taxes and adolescent body mass index. J Adolesc Health 45: 57-63.

21. Cawley J (2004) An economic framework for understanding physical activity and eating behaviors. Am J Prev Med 27: 117-125.

22. Magarey A, Daniels L, Boulton T, Cockington R (2003) Predicting obesity in early adulthood from childhood and parental obesity. Int J Obes 27: 505-513.

23. Albouy V, Davezies L, Debrand T (2010) Health expenditure models: a comparison using panel data. Econ Model 27: 791-803.

24. Simmonds M, llewelllyn A, Owen C, Wollacott C (2015) Predicting adult obesity from childhood obesity: a systematic review and meta-analysis. Obes Rev 17 95-107.

25. Stock J, Watson M (2009) Heteroskedasticity-robust standard errors for fixed effects panel data regression. NBER Technical Working Paper No. 323. 